\title{
Transformational leadership and employee voice: an affective perspective
}

\author{
Zhen Wang ${ }^{1}$, Shiyong $\mathrm{Xu}^{2^{*}}$, Yanling $\mathrm{Sun}^{3}$ and Yanjun Liu ${ }^{1}$
}

\author{
* Correspondence: xusy@ruc.edu.cn \\ ${ }^{2}$ Center for Human Resources \\ Development and Assessment, \\ School of Labor and Human \\ Resources, Renmin University of \\ China, Zhongguancun Street 59, \\ Haidian District, Beijing 100872, \\ China \\ Full list of author information is \\ available at the end of the article
}

\begin{abstract}
This study aims to examine the effect of transformational leadership on employee voice behavior. Specifically, this study investigates the mediating role of positive affect in linking transformational leadership with voice and the moderating role of over-qualification in influencing the mediation of positive affect. In particular, a twowave survey was conducted. A sample of 271 participants complete a questionnaire measuring transformational leadership, positive affect and various demographic variables in the first wave. Then, they complete a second questionnaire measuring perceived over-qualification and voice behavior 2 weeks later. We conduct a series of multiple regression analyses to test the model. The results show that positive affect partially mediated the relationship between transformational leadership and employee voice behavior. Over-qualification moderated the relationship between positive affect and voice. In addition, moderated mediation analyses reveal that positive affect mediates the relationship between transformational leadership and voice only for highly over-qualified employees. This study investigates a new method linking transformational leadership and voice from an affective perspective by finding the mediating effect of positive affect. We also verify the role of "energized to" process in shaping proactive behaviors. Finally, this study examines the boundary conditions of the effect of positive affect on voice.
\end{abstract}

Keywords: Employee, Self-efficacy, Transformational leadership, Voice, Positive affect, Perceived over-qualification, Proactive behaviors

\section{Introduction}

Voice behavior refers to an employee's constructive change-oriented communication that is intended to improve a situation (LePine and Van Dyne 2001). Generally, employee voice is a type of proactive work behavior that aims to improve the status quo (Parker and Collins 2010) and can foster organizational improvement and prevent organizational harm (Crant et al. 2011; Liang et al. 2012). Due to the potential benefits of voice, methods to motivate employees to voice their thoughts at work have become an important topic in organizational behavior research. Because leaders are usually the targets of voice and their attitudes and behaviors directly shape the willingness of employees to speak up (Morrison 2014), leader's behavior is considered an important antecedent that motivates employees to voice their thoughts. Transformational leadership may have a particular effect on employee voice behavior since it has been associated with personal and organizational changes and high performance (Bass and Riggio 2006). The four components of transformational leadership, namely: idealized

(c) The Author(s). 2019 Open Access This article is distributed under the terms of the Creative Commons Attribution 4.0 International License (http://creativecommons.org/licenses/by/4.0/), which permits unrestricted use, distribution, and reproduction in any medium, provided you give appropriate credit to the original author(s) and the source, provide a link to the Creative Commons license, and indicate if changes were made. 
influence, inspirational motivation, intellectual stimulation, and individualized consideration, will encourage voice behavior (Liu et al. 2010). Indeed, recent studies have found that transformational leadership is a more important leadership behavior on antecedents of voice than ethical leadership and abusive supervision (Chamberlin et al. 2017). However, the understanding of the underlying mechanism through which transformational leadership impacts voice is insufficient. Thus, this study focuses on the effect of transformational leadership on employee voice.

Voice is a typical type of proactive behavior (Parker and Collins 2010). Although previous studies have investigated the relationship between transformational leadership and voice, these studies are not sufficient (Svendsen and Joensson 2016). Researchers have revealed that cognitive factors, including psychological safety (Detert and Burris 2007), identification ( Liu et al. 2010), trust (Conchie et al. 2012) and the Pygmalion process (Duan et al. 2017), mediate the relationship between transformational leadership and voice. Although these findings are informative, the role of affective factors on voice and the "energized to" process of employee proactivity have not been examined in empirical studies of organizations (Detert and Burris 2007; Wang et al. 2012). To elucidate the facilitator of proactivity, Parker et al. (2010) proposed a proactive motivation model. Specifically, they identified three motivations. In particular, "can do" motivation refers to having a perception of capability of taking proactive actions, "reason to" motivation refers to the perception that engaging in proactive actions is worthwhile, and "energized to" motivation comprises affective experience that fuels individuals into engaging in proactivity (Bindl et al. 2012). Based on the proactive motivation model (Parker et al. 2010), previous studies on the antecedents of voice have mainly focused on the "can do" (i.e., psychological safety and voice self-efficacy) and "reason to" (i.e., identification) processes, whereas the "energized to" process has been largely overlooked. Indeed, the focus has been mostly on the rational and deliberate processes used by employees to weigh costs, benefits, and likely success (Morrison 2014). There is growing recognition that conscious cognitive processing is only part of the story and that the other part (i.e., the affective process) should be investigated (Morrison 2014). In addition, because voice is particularly challenging and demanding, having capability and reasons is not sufficient if an individual lacks energy to engage in such effortful activities. Therefore, identifying leaders who can affectively energize subordinates to voice is crucial.

This study draws on the proactive motivation model and broaden-and-build theory (Fredrickson 1998; Fredrickson 2001) to suggest that transformational leaders can cultivate positive affect to promote employee voice behavior. We propose that positive affect is likely to be an energizing mechanism that motivates employees to voice their thoughts because it broadens a person's thought-action repertoire (Fredrickson 1998, Fredrickson 2001). Therefore, our first goal is to investigate affective factors as a mechanism that mediates transformational leadership and employee voice to complement the existing cognitive perspective. In addition, we investigate the boundary condition of the mediating effect of positive affect. The "energized to" effect may be strengthened with "can do" and "reason to" processes. Specifically, we suggest that positive affect will be more critical for motivating voice behavior of employees with highly perceived over-qualification (Erdogan et al. 2011). Employees may focus on their surplus job capacity and have a positive view of their job competence and efficacy (Zhang et al. 2016). 
Indeed, over-qualified employees have been shown to exhibit higher supervisor-rated performance (Fine 2007; Fine and Nevo 2008) and task performances (Erdogan and Bauer 2009; Holtom et al. 2002). Therefore, our second goal is to explore the moderating role of perceived over-qualification between positive affect and voice to clarify when transformational leadership can make greater contributions to employee voice behavior through positive affect.

This study makes several contributions to the literature. First, drawing on the proactive motivation model and broaden-and-build theory, we extend previous voice research by investigating a different process (i.e., affective process) linking transformational leadership and voice behavior. Specifically, we identify the mediating role of positive affect and thus verify the ability of the "energized to" process to motivate proactivity (Parker et al. 2010). This examination helps substantiate the affect-as-resource perspective in understanding the influence of positive affect on employee voice behavior. Second, we examine the moderating effect of over-qualification and clarify the boundary condition of the effect of a positive effect. Specifically, we explore the potentially positive side of perceived over-qualification (i.e., positive affect is more likely to promote employee voice behavior when perceived over-qualification is high). Overall, as an extension of previous research, we propose a second-stage moderated mediation model (Hayes 2013) to investigate the underlying mechanisms and boundary conditions that may explain how and when transformational leadership relates to voice behavior from an affective perspective.

\section{Theoretical background and hypothesis development}

\section{Transformational leadership and employee voice}

Transformational leadership consists of four sub-dimensions: (1) idealized influence, in which the leaders are admired, respected, and trusted; (2) inspirational motivation, which reflects how leaders motivate and inspire employees by providing meaning and challenge in their work; (3) intellectual stimulation, which refers to stimulating employees' efforts to be innovative and creative by questioning assumptions, reframing problems, and approaching old situations in new ways; and (4) individualized consideration, which involves leaders paying more attention to each individual follower's needs for achievement and growth by acting as a coach or mentor (Bass 1985; Bass and Riggio 2006). Previous studies have consistently suggested that transformational leadership is related to followers' positive attitudes and performances (e.g., Perko et al. 2014; Chan and Mak 2014).

Transformational leadership may be more likely to encourage employees to provide constructive suggestions for their organizations. First, a transformational leader may signal and encourage voice behavior by being a good listener, personally interacting with employees, and giving them the room and safety to express themselves (Svendsen and Joensson 2016). Second, transformational leaders stimulate and empower employees to question the status quo and think outside of the box (Schmitt et al. 2016). Previous empirical research has examined the psychological mechanisms underlying how transformational leadership influences employee voice from cost-benefit analysis, self-concept and Pygmalion perspectives (Duan et al. 2017). Specifically, Detert and Burris (2007) suggested that transformational leaders were more likely to cultivate employees' psychological safety, which alleviated negative concerns about speaking up 
and thus motivated employee voice behavior. From a self-concept perspective, Liu et al. (2010) indicated that transformational leaders were more likely to evoke employees' personal identification with the leader and build a strong relational self that motivated employees to speak up. Furthermore, from a Pygmalion perspective, Duan et al. (2017) found that transformational leadership influenced employee voice through leaders' voice expectations and employees' voice role perceptions. Thus, in this study we suggest transformational leadership is positively related to employee voice behavior and investigate this relationship from a new affective perspective.

\section{The mediating effect of positive affect}

Affect is used as an umbrella term for emotions, moods, and traits (Barsade and Gibson 2007). Researchers recognize two categories of affect: trait affect and state affect. Trait affect reflects an individual's tendency to produce a specific emotion across different situations, whereas state affect refers to an individual's affect at a given point in time (Watson et al. 1988). Some scholars have argued that state affect has a more direct impact on human behavior than trait affect (Elfenbein 2007). In addition, a previous study found that positive affect was positively associated with positive behaviors, such as organizational citizenship (Shockley et al. 2012). Therefore, in this study, we focus on the positive affect and assume that it plays a critical role in linking transformational leadership to voice.

First, we elaborate why transformational leadership may promote employees' experiences of positive affect. Transformational leadership has an intense emotional component (Bass 1985) and may elicit feelings of happiness and enthusiasm in employees by providing inspirational and emotional appeals (Bono et al. 2007). In addition, both positive affect and motivation of energized states can be implicitly adopted and internalized by followers via an emotional contagion process (Bono and Ilies 2006). Sy et al. (2005) also reported that group members experienced more positive moods and exhibited greater coordination when their leaders were in a positive mood.

We also suggest that individuals with positive affect are more likely to voice. Drawing from the broaden-and-build theory, the experience of certain positive emotions prompts individuals to discard time-tested or automatic behavioral scripts and to pursue novel, creative, and often unscripted paths of thought and action (Fredrickson 2001). We assume that positive affect builds and broadens an individual's physical, intellectual, and social resources, which may help initiate effortful and goal-oriented activities, such as proactive behavior (Sonnentag 2003). This assumption can be elaborated based on the following rationales. First, when employees are in a positive affective state, they are more likely to set challenging goals (Ilies and Judge 2005) and engage in proactive goal generation. As a result, employees may actively propose ideas and suggestions to change the status quo of their organizations and thus exhibit more voice behavior. Second, positive affect potentially promotes more effective and proactive goal striving. Because positive affect makes an individual's personal resources to be more durable than transient emotional states (Fredrickson 1998), it helps employees handle future problematic scenarios and sustain more voice behavior. 
Overall, we expect that transformational leadership will first shape positive affect and then contribute to voice. Therefore, we propose the following hypothesis:

Hypothesis 1: Positive affect will mediate the relationship between transformational leadership and employee voice behavior.

\section{The moderating effect of perceived over-qualification}

Over-qualification, denotes a situation in which employees possess qualifications, such as education, work experience, and skills, which extend beyond their job requirements (Erdogan et al. 2011), has become a prevalent phenomenon in some countries (Deng et al. 2018). In particular, perceived over-qualification refers to employees' subjective feelings of being underutilized (i.e., employees' awareness of the extent to which there is a directional mismatch between their qualifications and the job requirements) (Erdogan and Bauer 2009; Liu and Wang 2012). Perceived over-qualification is usually measured by comparing an employee's education and skillset with those stated in the job description (Deng et al. 2018) and tends to be a more proximal predictor of employee attitude and behavior because it reflects reality experienced by the individual. For example, perceived over-qualification has been found to have implications for employee performances (Erdogan and Bauer 2009; Hu et al. 2015). Thus in this study, we focus on perceived over-qualification represented by the employees' perceptions that they have more education, training or experience than is required by their jobs.

Although previous studies have suggested that over-qualification has a harmful influence on employees' performances and attitudes toward their jobs (Verhaest and Omey 2006), over-qualified employees may also take proactive steps to change their work situations (Maynard et al. 2006). In particular, we assume that perceived over-qualification moderates the relationship between positive affect and employee voice. As mentioned previously, individuals with positive affect possess more physical, intellectual, and social resources, which may help initiate effortful and goal-oriented activities, such as voice (Parker et al. 2010). However, this "energized to" effect may be strengthened by "can do" and "reason to" processes. Thus, individuals with positive affect may be more likely to exhibit voice when they perceive that they have the capability and reason to voice.

Firstly, over-qualified employees may possess high self-efficacy. It makes them possess high "can do" motivation and will strengthen the effect of "energized to" motivation (i.e., positive affect). Indeed, voice behavior is effortful, risky and challenging (LePine and Van Dyne 2001), and thus employees having energy, together with high self-efficacy, are more likely to voice. Over-qualified employees may appreciate their surplus knowledge, skills, and abilities (KSAs) and react to this discrepancy in a positive way (Zhang et al. 2016). Over-qualified employees have surplus talents and perceived competence in their expanded roles, which makes them believe that their suggestions will be more effective for leaders or organizations and thus enhances their voice self-efficacy. As mentioned previously, employees in a positive affective state are more likely to set challenging goals and engage in proactive goal generation (Ilies and Judge 2005). Highly over-qualified employees may strengthen the "energized to" process of the positive affect on voice because they are more confident that the proactive behavior 
is effective. On the other hand, if individuals are not confident, they will be less likely to engage in voice behavior even if they are energized. That is, individuals with positive affect are more likely to exhibit voice when they perceive that they have the capability to voice.

Secondly, over-qualified employees may possess expanded responsibilities and have a need to maintain positive self-evaluation. It makes them possess high "reason to" motivation and will strengthen the effect of "energized to" motivation (i.e., positive affect). Individuals need to know the benefits associated with being proactive to change a particular target (Parker et al. 2010). Therefore, individuals having energy, as well as good reasons, are more likely to voice. Previous studies showed that over-qualification might drive employees to increase their responsibilities, perhaps by negotiating with their manager, and to engage in job innovation by generating constructive suggestions (Erdogan et al. 2011). In addition, Liu and Wang (2012) proposed that the extent to which one could utilize his/her talent at work was an important source of self-evaluation at the workplace. When employees are able to apply their talents on their work assignments and make valuable contributions, they feel that their organizations value their KSAOs (knowledge, skills, abilities, and other characteristics), which leads to positive self-evaluations (Liu and Wang 2012). Thus, to maintain a good self-evaluation, over-qualified employees are likely to take on extra responsibilities and make their work more intrinsically motivating, which provides a compelling "reason to" engagement in proactive behavior. When employees are in positive affect, they are energetic and full of emotional resources (Sonnentag 2003). In this situation, they are more likely to exhibit voice behavior if they believe there are good reasons for this practice. On the other hand, if individuals lack sufficient reason to voice, they are less likely to demonstrate voice even if they are full of emotional resources.

Thus, we propose a moderating effect of perceived over-qualification:

Hypothesis 2: Perceived over-qualification moderates the relationship between positive affect and voice. In particular, the relationship between positive affect and employee voice behavior is stronger for employees who perceive high over-qualification.

\section{The second-stage moderated mediation model}

Based on the proactive motivation model and broaden-and-build theory, our hypothesis implies a moderated mediation process (Edwards and Lambert 2007). In particular, transformational leadership will elicit their employees' positive affect, which will enhance personal efforts to voice ideas and promote the development of their organization. In addition, the positive relationship between positive affect and voice will be strengthened when employees perceive high over-qualification. Individuals with positive affect possess more physical, intellectual, and social resources, which may initiate effortful and goal-oriented activities, such as voice (Parker et al. 2010). However, this "energized to" effect will be strengthened by "can do" and "reason to" processes. Thus, individuals with positive affect will be more likely to exhibit voice when they perceive that they have the capability and reason to voice. Furthermore, when over-qualification is high, individuals possess 
high self-efficacy and have good reasons to voice. Together with the energy from transformational leaders, individuals are more likely to voice. Thus, it will strengthen the indirect effect of transformational leadership on employee voice via positive affect. In sum, based on proactive motivation model, we propose a second-stage moderated mediation model in which perceived over-qualification moderates the indirect relationship between transformational leadership and employee voice via positive affect.

Hypothesis 3: The indirect effect of transformational leadership on employee voice behavior through positive affect is stronger for employees who perceive high overqualification.

\section{Methods}

\section{Sample and procedures}

The sample of individuals investigated in this study was obtained from employees at an internet technology (IT) outsourcing company in China. This company provides assistant services for large IT firms. Because these tasks are relatively routine, the job requirement for education is not very high. Many employees hold college degrees or received program training from vocational schools. Overall, 330 employees participated in the first-wave survey, and 313 employees completed it for a response rate of $94.8 \%$. Then, we sent questionnaires to these 313 employees in the second-wave survey; a total of 271 of the employees completed both questionnaires with usable information for a total usable response rate of $82.1 \%$ for the two waves. Among the participants, $58.2 \%$ were female, $41.8 \%$ were male; $26.9 \%$ finished high school, $27.2 \%$ completed college, $28.4 \%$ received a bachelor's degree, and $17.5 \%$ received a master's degree. The mean age and mean length of organizational tenure were 31.49 years $(S D=7.23)$ and 9.61 years $(\mathrm{SD}=7.19)$, respectively.

The questionnaires were distributed in two waves. In the first wave, the participants completed a questionnaire assessing their immediate supervisor's transformational leadership, their positive affect, their perceived over-qualification and various demographic variables (Questionnaire A). The questionnaires were sent to the employees via email. To ensure anonymity, we asked the participants to return the completed questionnaires via a public email account created for the study. Two weeks later, we sent the participants another questionnaire measuring voice (Questionnaire B). To ensure that we would be able to match the two questionnaires for each respondent, we placed an identifying mark on each pair of questionnaires.

\section{Measures}

Transformational leadership was measured with 20 items from the Multifactor Leadership Questionnaire (MLQ; Bass 1985), which includes items that measure idealized influence, inspirational motivation, intellectual stimulation, and individualized consideration. Transformational leadership was rated on a 5-point Likert scale ( $1=$ never to $5=$ very often). One sample item is "Articulates a compelling vision of the future." Several studies have indicated a high-order factor for this scale and have used 
a composite of all 20 items to measure transformational leadership (Avolio et al. 2004; Svendsen and Joensson 2016) $(\alpha=0.96)$.

Voice was measured using 10 items from Liang et al.'s (2012) voice scale. A 5-point response scale $(1=$ strongly disagree to $5=$ strongly agree) was used to assess voice. One sample item is "Proactively suggests new projects that are beneficial to the work unit." The 10 items were averaged to obtain a total score of voice $(\alpha=0.89)$.

Positive affect was measured with 10 items related to pleasure from the Job-Related Affective Well-Being Scale (JAWS; Van Katwyk et al. 2000). A 5-point response scale $(1=$ never to $5=$ very often) was used to assess job-related positive affect. The respondents were instructed to reflect their affective state over the last week. One sample item is "My job makes me feel at ease." The 10 items were averaged to obtain a total score of positive affect $(\alpha=0.92)$.

Perceived over-qualification was measured using 3 items from Khan and Morrow's (1991) scale. One sample item is "My formal education over-qualifies me for my present job." The respondents used a 5-point Likert scale ranging from 1 (strongly disagree) to 5 (strongly agree). The 3 items were averaged to obtain a total score of perceived over-qualification $(\alpha=0.96)$.

We controlled for gender, length of organizational tenure, and education. Previous research suggests a positive relationship between these three variables and voice (Duan et al. 2017; Zhang et al. 2016; Tornau and Frese 2013). A higher level of education provides employees with professional knowledge and skills that help them engage in constructive, change-oriented behavior. Employees with longer tenure develop more profound knowledge about the organization and its routines, which can help them decide when to speak up with their own thoughts.

\section{Results}

\section{Preliminary analysis}

We performed a confirmatory factor analysis (CFA) to examine the distinctiveness of the four substantial constructs in this study: transformational leadership, positive affect, perceived over-qualification and voice. Table 1 shows a comparison of the various models. The hypothesized 4-factor model (Model 1) shows a satisfactory fit with the data $\left(\chi^{2}=71.50 ; d f=59 ; \mathrm{GFI}=0.96\right.$; $\mathrm{CFI}=0.99$; $\mathrm{TLI}=0.99$; $\left.\mathrm{RMSEA}=0.03\right)$ and a better fit than all alternative models. In this 4-factor model, all variables load significantly onto their respective factors. These findings suggest that the variables are distinguishable (Podsakoff et al. 2012).

Table 1 Confirmatory factor analysis for the main constructs

\begin{tabular}{lllllll}
\hline Model & $x^{2}(d f)$ & $\Delta x^{2}(\Delta d f)$ & GFI & CFI & TLI & RMSEA \\
\hline Model 1 & $71.50(59)$ & & 0.96 & 0.99 & 0.99 & 0.03 \\
Model 2 & $459.48(62)$ & $387.98(3)$ & 0.78 & 0.77 & 0.71 & 0.15 \\
Model 3 & $788.62(64)$ & $717.12(5)$ & 0.67 & 0.59 & 0.50 & 0.21 \\
Model 4 & $987.46(65)$ & $915.96(6)$ & 0.62 & 0.47 & 0.37 & 0.23 \\
\hline
\end{tabular}

Notes. Model 1 = transformational leadership, positive affect, perceived over-qualification, voice; Model $2=$ transformational leadership + positive affect, perceived over-qualification, voice; Model $3=$ transformational leadership + positive affect + perceived over-qualification, voice; Model $4=$ transformational leadership + positive affect + perceived over-qualification + voice. All $X^{2}$ differences are significant at $p<0.001$ 
Table 2 Means, standard deviations, and correlations among the study variables

\begin{tabular}{lllllllll}
\hline Variable & M & SD & 1 & 2 & 3 & 4 & 5 & 6 \\
\hline Gender & 0.42 & 0.49 & & & & & & \\
Tenure & 9.61 & 7.19 & 0.12 & & & & \\
Education & 3.37 & 1.06 & $0.22^{* *}$ & 0.09 & & & \\
Transformational leadership & 2.91 & 0.86 & 0.04 & -0.04 & 0.10 & & \\
Perceived over-qualification & 3.36 & 0.79 & 0.01 & $0.16^{* *}$ & 0.01 & -0.03 & & \\
Positive affect & 2.58 & 0.71 & 0.07 & $0.13^{*}$ & $0.18^{* *}$ & $0.45^{* *}$ & 0.10 & \\
Voice & 3.24 & 0.60 & $0.16^{*}$ & $0.19^{* *}$ & $0.13^{*}$ & $0.22^{* *}$ & $0.19^{* *}$ & $0.28^{* *}$ \\
\hline
\end{tabular}

Notes. $n=271 .{ }^{* *} p<0.01,{ }^{*} p<0.05$

Table 2 presents the means, standard deviations and correlations among all variables. Transformational leadership is positively associated with positive affect $(r=0.45, p<0.01)$ and voice $(r=0.22, p<0.01)$. In addition, voice is positively related to positive affect $(r=0.28, p<0.01)$ and perceived over-qualification $(r=0.19, p<0.01)$.

\section{Hypothesis testing}

We used SPSS PROCESS to test the hypotheses (Hayes 2013) and the results are shown in Table 3. As shown in Model 1, transformational leadership is positively associated with positive affect $(\beta=0.37, p<0.01)$. Model 2 shows that positive affective state is still associated with voice when both this variable and transformational leadership are included in the regression analysis $(\beta=0.16, p<0.01)$. The coefficient of transformational leadership is not significant $(\beta=0.09, p>0.05)$. This result suggests that positive affect mediates the relationship between transformational leadership and voice. The indirect effect is 0.06 and bootstrapped $95 \%$ confidence interval $(0.01,0.12$; excluding zero). These results indicate that the indirect effect is positive and significant, providing support for Hypothesis 1.

To examine the moderating effect of over-qualification, we conducted a moderated hierarchical regression analysis with voice as the dependent variable. As shown in Model 4, after controlling for the main effects, the interaction between positive affect and perceived over-qualification is significant $\left(\beta=0.15, p<0.01, \Delta R^{2}=0.03\right)$. Figure 1 depicts the interaction with simple slopes. For individuals who did not perceive

Table 3 The hierarchical regression analysis results (Hypotheses 1, 2 and 3)

\begin{tabular}{lllll}
\hline Variable & PSA & \multicolumn{2}{l}{ Voice } \\
\cline { 3 - 5 } & Model 1 & Model 2 & Model 3 & Model 4 \\
\hline Gender & 0.00 & 0.15 & $0.14^{*}$ & $0.16^{*}$ \\
Tenure & $0.02^{*}$ & $0.01^{*}$ & $0.01^{*}$ & $0.01^{*}$ \\
Education & $0.08^{*}$ & 0.02 & 0.02 & 0.03 \\
Transformational leadership & $0.37^{* *}$ & 0.09 & $0.10^{*}$ & $0.10^{*}$ \\
PSA & & $0.16^{* *}$ & $0.15^{* *}$ & $0.12^{*}$ \\
POQ & & & $0.13^{* *}$ & $0.12^{* *}$ \\
PSAXPOQ & & & & $0.15^{* *}$ \\
$R^{2}$ & $0.24^{* *}$ & $0.14^{* *}$ & $0.16^{* *}$ & $0.19^{* *}$ \\
$\Delta R^{2}$ & & & $0.02^{* *}$ & $0.03^{* *}$ \\
\hline
\end{tabular}

Notes. $n=271$. PSA Positive affect, POQ Perceived over-qualification. ${ }^{* *} p<0.01,{ }^{*} p<0.05$ 


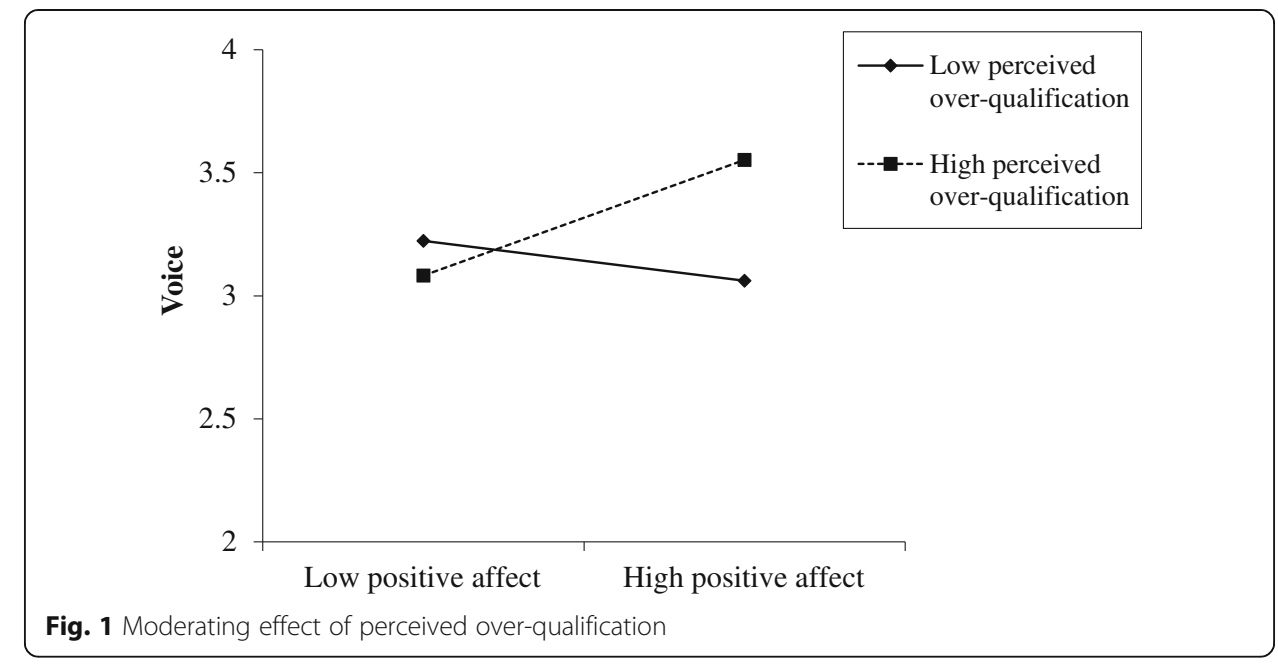

themselves to be over-qualified (those with scores at least 1 SD below the mean perceived over-qualification score), the relationship between positive affect and voice is not significant $(\beta=-0.03, p>0.10)$. For individuals who perceived themselves as being over-qualified (those with scores at least $1 \mathrm{SD}$ above the mean score), the relationship between positive affect and voice is significant $(\beta=0.27, p<0.01)$. Theseresults indicate that the relationship between positive affect and voice is positive and stronger for individuals who perceive themselves to be over-qualified, which support Hypothesis 2.

The results show that the indirect effect on voice is significant based on 5000 bootstrap samples to generate bias-corrected bootstrap 95\% confidence intervals. The indirect effect $=0.06, \mathrm{SE}=0.02$, bias-corrected bootstrap 95\% CI (0.01, 0.10; excluding zero). The conditional indirect effects were examined at three different levels of perceived over-qualification, including low perceived over-qualification (1 SD below the mean), average perceived over-qualification and high perceived over-qualification (1 SD above the mean) while controlling for gender, tenure, and education. The indirect effect of transformational leadership has a significant association with voice via positive affect for participants with high and average perceived over-qualification. Specifically, when the perceived over-qualification is high, the indirect effect $=0.09, \mathrm{SE}=0.03$, and bias-corrected bootstrap $95 \% \mathrm{CI}=(0.03,0.15$ : excluding zero $)$. When the perceived over-qualification is average, the indirect effect $=0.05, \mathrm{SE}=0.02$, and bias-corrected bootstrap $95 \% \mathrm{CI}=(0.004,0.09$; excluding zero). However, the indirect effect is not significant for participants with low perceived over-qualification. The indirect effect $=0.00$, $\mathrm{SE}=0.03$, and bias-corrected bootstrap $95 \% \mathrm{CI}=(-0.05,0.06$; including zero $)$ for this group. Thus, Hypothesis 3 is supported.

\section{Conclusion and discussion}

\section{Theoretical implications}

Our study has advanced the understanding of the underlying mechanisms of employee voice. The results of the present study indicate that employees with transformational leaders are more likely to engage in voice and that positive affect mediates the association between transformational leadership and voice. The results 
also suggest that perceived over-qualification moderates the association between positive affect and voice. Furthermore, the indirect effect of transformational leadership on voice via positive affect is moderated by perceived over-qualification. The results of the present study contribute to the literature on transformational leadership and voice in several ways.

First, this study extends our understanding of the mechanisms underlying the relationship between transformational leadership and voice. Transformational leaders can promote employee voice behavior through positive affect by reflecting an energizing process and motivating proactivity (Parker et al. 2010). Based on the proactive motivation model, we assume that transformational leaders arouse employees' positive affect, which can in turn broaden and build personal resources to promote employee voice behavior. In most previous studies, researchers used the cognitive perspective to explain how transformational leadership was related to employee voice and argued that employees believed that they would receive more resources when they provided suggestions, such as supervisor recognition and organizational support, and that cognitive factors could elucidate the black box between transformational leadership and voice. However, our study suggests that this black box may also be clarified from an affective perspective.

Second, our study is the first to demonstrate that the association between positive affect and voice is moderated by perceived over-qualification. This study focused on a bright side of perceived over-qualification that could positively influence employees' pro-organizational behaviors. Previous studies have typically examined the negative consequences of perceived over-qualification (e.g., Maynard et al. 2006) and generally have assumed that over-qualification breeds undesirable work conditions. Although perceived over-qualification implies a discrepancy between one's surplus ability and inadequate ability utilization, this discrepancy is not necessarily negative (Zhang et al. 2016). The results of this study indicate that perceived over-qualification can encourage employees to feel good about their competence and contribution to the organization, which substantially benefits organizations by transforming human capital into competitive advantages (Fuller et al. 2012).

\section{Practical implications}

In addition to the theoretical contribution discussed above, the study also increases our understanding of certain managerial practices concerning how transformational leaders motivate employees to speak up with their suggestions. First, our results indicate that leaders who use transformational strategies can evoke employees by generating positive affect to stimulate more employee voice behavior. Therefore, transformational leaders should focus on utilizing the strategy of inspirational motivation to influence employee affect. Furthermore, leaders should give employees more individualized consideration and prioritize the creation of a favorable affective workplace environment. Supervisors should also directly invite employees to speak up through participatory supervisory practices. Employees who perceive themselves as valued and respected by their supervisors are more likely to generate positive affect and in turn engage in more voice.

This study also indicates that over-qualification could strengthen the effect of positive affect on voice behavior. Employees with positive affect are more likely to voice when they perceive themselves as over-qualified. Over-qualification is instrumental to 
enhance the effect of "energized to" path of proactive motivation. Indeed, over-qualified employees can leverage their surplus talents to feel good and do well. Erdogan et al. (2011) also suggested that overqualified employees might present unique advantages to hiring organizations. Therefore, to retain and motivate over-qualified employees, leaders may consider placing them in positions that require particularly high voice (Luksyte et al. 2011). In this way, it is likely to stimulate the potential of over-qualified employees, especially facilitating employees with positive affect to speak up.

Moreover, at a societal level, the Chinese national educational level has increased dramatically over the last two decades, resulting in serious criticisms related to a suspected waste of qualified personnel (Wu and Zhao 2010). However, our findings suggest that over-qualification is not without some benefits. In a positive affective state, an over-qualified individual is more likely to engage in voice than other employees, and voice is important for constructing the innovative society advocated by the Chinese government (Xu and Xiao 2008).

\section{Limitations and future research}

The study has several limitations. First, to assess the affective state, we collected data in two waves separated by a two-week interval. However, this design could not test the causal effect of the key variables. A more rigorous design is needed to explore the causal relationships among these variables. Second, we used employee self-reported questionnaires, which can lead to common method bias (Podsakoff et al. 2003). Although the two-wave design should reduce common method bias and the confirmatory factor analysis showed that the bias did not seriously impact our results, use of leader ratings for employee voice behavior would be a better option in future research. Third, we failed to control for some important cognitive variables that might influence the simple association between positive affect and voice. We have focused on the influence of affective factors on voice in this study, but we believe that researchers should examine the joint influence of cognition and affect on voice.

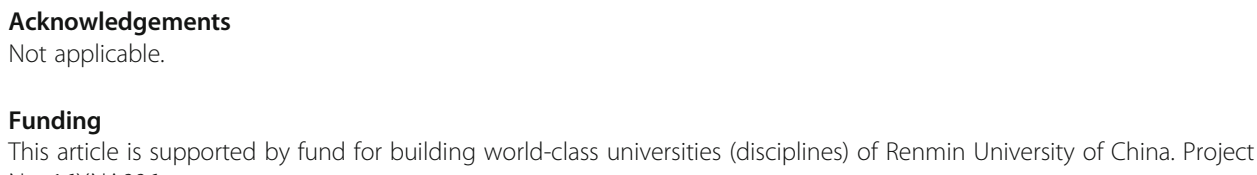

\section{Authors' information}

Zhen Wang (Ph.D., University of Chinese Academy of Sciences) is an associate professor in School of Labor and Human Resources, Renmin University of China. His research interests are leadership, effective teamwork, and employee well-being. His research appears in Personnel Psychology, Journal of Vocational Behavior, Leadership Quarterly, Journal of Business Ethics, Human Resource Management Journal, Journal of Occupational Health Psychology and Asia Pacific Journal of Management.

Shiyong Xu (Ph.D., Beijing Normal University) is a professor in School of Labor and Human Resources, Renmin University of China. His research interests are leadership, affect, CWB. His Research appears in Management World and Acta Psychologica Sinica.

Yanling Sun (Ph.D., Renmin University of China) is an assistant researcher in Chinese Academy of Personnel Science. Her research interests are leadership and voice.

Yanjun Liu is a Ph.D. candidate in School of Labor and Human Resources, Renmin University of China. Her research interests are leadership and CWB. 


\section{Competing interests}

The authors declare that they have no competing interests.

\section{Publisher's Note}

Springer Nature remains neutral with regard to jurisdictional claims in published maps and institutional affiliations.

\section{Author details}

${ }^{1}$ School of Labor and Human Resources, Renmin University of China, Zhongguancun Street 59, Haidian District, Beijing 100872, China. ${ }^{2}$ Center for Human Resources Development and Assessment, School of Labor and Human Resources, Renmin University of China, Zhongguancun Street 59, Haidian District, Beijing 100872, China. ${ }^{3}$ Chinese Academy of Personnel Science, Beijing, China.

Received: 9 March 2018 Accepted: 3 January 2019

Published online: 21 January 2019

\section{References}

Avolio, B. J., Zhu, W., Koh, W., \& Bhatia, P. (2004). Transformational leadership and organizational commitment: Mediating role of psychological empowerment and moderating role of structural distance. Journal of Organizational Behavior, 25(8), 951-968.

Barsade, S. G., \& Gibson, D. E. (2007). Why does affect matter in organizations? Academy of Management Perspectives, 21(1), 36-59.

Bass, B. M. (1985). Leadership and performance beyond expectations. New York: Free Press.

Bass, B. M., \& Riggio, R. E. (2006). Transformational leadership. Mahwah: Erlbaum.

Bindl, U. K., Parker, S. K., Totterdell, P., \& Hagger-Johnson, G. (2012). Fuel of the self-starter: How mood relates to proactive goal regulation. Journal of Applied Psychology, 97(1), 134-150.

Bono, J. E., Foldes, H. J., Vinson, G., \& Muros, J. P. (2007). Workplace emotions: The role of supervision and leadership. Journal of Applied Psychology, 92(5), 1357-1367.

Bono, J. E., \& Ilies, R. (2006). Charisma, positive emotions and mood contagion. The Leadership Quarterly, 17(4), 317-334.

Chamberlin, M., Newton, D. W., \& Lepine, J. A. (2017). A meta-analysis of voice and its promotive and prohibitive forms: Identification of key associations, distinctions, and future research directions. Personnel Psychology, 70(1), 11-71.

Chan, S. C. H., \& Mak, W. M. (2014). Transformational leadership, pride in being a follower of the leader and organizational commitment. Leadership \& Organization Development Journal, 35(8), 674-690.

Conchie, S. M., Taylor, P. J., \& Donald, I. J. (2012). Promoting safety voice with safety-specific transformational leadership: The mediating role of two dimensions of trust. Journal of Occupational Health Psychology, 17(1), 105-115.

Crant, J. M., Kim, T. Y., \& Wang, J. (2011). Dispositional antecedents of demonstration and usefulness of voice behavior. Journal of Business and Psychology, 26(3), 285-297.

Deng, H., Guan, Y., Wu, C. H., Erdogan, B., Bauer, T., \& Yao, X. (2018). A relational model of perceived overqualification: the moderating role of interpersonal influence on social acceptance. Journal of Management, 44(8), 3288-3310.

Detert, J. R., \& Burris, E. R. (2007). Leadership behavior and employee voice: Is the door really open? Academy of Management Journal, 50(4), 869-884.

Duan, J., Li, C., Xu, Y., \& Wu, C. H. (2017). Transformational leadership and employee voice behavior: A Pygmalion mechanism. Journal of Organizational Behavior, 38(5), 650-670.

Edwards, J. R., \& Lambert, L. S. (2007). Methods for integrating moderation and mediation: A general analytical framework using moderated path analysis. Psychological Methods, 12(1), 1-22.

Elfenbein, H. A. (2007). Emotion in organizations: A review and theoretical integration. Academy of Management Annals, 1(1), $315-386$.

Erdogan, B., \& Bauer, T. N. (2009). Perceived overqualification and its outcomes: The moderating role of empowerment. Journal of Applied Psychology, 94(2), 557-565.

Erdogan, B., Bauer, T. N., Peiró, J., \& Truxillo, D. M. (2011). Overqualified employees: Making the best of a potentially bad situation for individuals and organizations. Industrial and Organizational Psychology, 4(2), 215-232.

Fine, S. (2007). Overqualification and selection in leadership training. Journal of Leadership \& Organizational Studies, $14(1), 61-68$.

Fine, S., \& Nevo, B. (2008). Too smart for their own good? A study of perceived cognitive overqualification in the workforce. The International Journal of Human Resource Management, 19(2), 346-355.

Fredrickson, B. L. (1998). What good are positive emotions? Review of General Psychology, 2(3), 300-319.

Fredrickson, B. L. (2001). The role of positive emotions in positive psychology. American Psychologist, 56(3), 218-226.

Fuller, J. B., Marler, L. E., \& Hester, K. (2012). Bridge building within the province of proactivity. Journal of Organizational Behavior, 33(8), 1053-1070.

Hayes, A. F. (2013). Introduction to mediation, moderation, and conditional process analysis: A regression-based approach. New York: Guilford Press.

Holtom, B. C., Lee, T. W., \& Tidd, S. T. (2002). The relationship between work status congruence and work-related attitudes and behaviors. Journal of Applied Psychology, 87(5), 903-915.

Hu, J., Erdogan, B., Bauer, T. N., Jiang, K., Liu, S., \& Li, Y. (2015). There are lots of big fish in this pond: The role of peer overqualification on task significance, perceived fit, and performance for overqualified employees. Journal of Applied Psychology, 100(4), 1228-1238.

llies, R., \& Judge, T. A. (2005). Goal regulation across time: The effects of feedback and affect. Journal of Applied Psychology, 90(3), 453-467.

Khan, L. J., \& Morrow, P. C. (1991). Objective and subjective underemployment relationships to job satisfaction. Journal of Business Research, 22(3), 211-218. 
LePine, J. A., \& Van Dyne, L. (2001). Voice and cooperative behavior as contrasting forms of contextual performance: Evidence of differential relationships with big five personality characteristics and cognitive ability. Journal of Applied Psychology, 86(2), 326-336.

Liang, J., Farh, C. I., \& Farh, J. (2012). Psychological antecedents of promotive and prohibitive voice: A two-wave examination. Academy of Management Journal, 55(1), 71-92.

Liu, S., \& Wang, M. (2012). Perceived overqualification: A review and recommendations for research and practice. Research in Occupational Stress and Well-being, 10, 1-42.

Liu, W., Zhu, R., \& Yang, Y. (2010). I warn you because I like you: Voice behavior, employee identifications and transformational leadership. The Leadership Quarterly, 21(1), 189-202.

Luksyte, A., Spitzmueller, C., \& Maynard, D. C. (2011). Why do overqualified incumbents deviate? Examining multiple mediators. Journal of Occupational Health Psychology, 16(3), 279-296.

Maynard, D. C., Joseph, T. A., \& Maynard, A. M. (2006). Underemployment, job attitudes, and turnover intentions. Journal of Organizational Behavior, 27(4), 509-536.

Morrison, E. W. (2014). Employee voice and silence. Annual Review of Organizational Psychology and Organizational Behavior 1(1), 173-197.

Parker, S. K., Bindl, U. K., \& Strauss, K. (2010). Making things happen: A model of proactive motivation. Journal of Management, 36(4), 827-856.

Parker, S. K., \& Collins, C. G. (2010). Taking stock: Integrating and differentiating multiple proactive behaviors. Journal of Management, 36(3), 633-662.

Perko, K., Kinnunen, U., \& Feldt, T. (2014). Transformational leadership and depressive symptoms among employees: Mediating factors. Leadership \& Organization Development Journal, 35(4), 286-230.

Podsakoff, P. M., MacKenzie, S. B., Lee, J. Y., \& Podsakoff, N. P. (2003). Common method biases in behavioral research: A critical review of the literature and recommended remedies. Journal of Applied Psychology, 88(5), 879-903.

Podsakoff, P. M., Mackenzie, S. B., \& Podsakoff, N. P. (2012). Sources of method bias in social science research and recommendations on how to control it. Annual Review of Psychology, 63, 539-569.

Schmitt, A., Den, H. D. N., \& Belschak, F. D. (2016). Transformational leadership and proactive work behaviour: A moderated mediation model including work engagement and job strain. Journal of Occupational and Organizational Psychology, 89(3), 588-610.

Shockley, K. M., Ispas, D., Rossi, M. E., \& Levine, E. L. (2012). A meta-analytic investigation of the relationship between state affect, discrete emotions, and job performance. Human Performance, 25(5), 377-411.

Sonnentag, S. (2003). Recovery, work engagement, and proactive behavior: A new look at the interface between nonwork and work. Journal of Applied Psychology, 88(3), 518-528.

Svendsen, M., \& Joensson, T. S. (2016). Transformational leadership and change related voice behavior. Leadership \& Organization Development Journal, 37(3), 357-368.

Sy, T., Côté, S., \& Saavedra, R. (2005). The contagious leader: Impact of the leader's mood on the mood of group members, group affective tone, and group processes. Journal of Applied Psychology, 90(2), 295-305.

Tornau, K., \& Frese, M. (2013). Construct clean-up in proactivity research: A meta-analysis on the nomological net of workrelated proactivity concepts and their incremental validities. Applied Psychology, 62(1), 44-96.

Van Katwyk, P. T., Fox, S., Spector, P. E., \& Kelloway, E. K. (2000). Using the job-related affective well-being scale (JAWS) to investigate affective responses to work stressors. Journal of Occupational Health Psychology, 5(2), 219-230.

Verhaest, D., \& Omey, E. (2006). The impact of overeducation and its measurement. Social Indicators Research, 77(3), 419-448.

Wang, A., Hsieh, H., Tsai, C., \& Cheng, B. (2012). Does value congruence lead to voice? Cooperative voice and differentiated transformational leadership. Management and Organization Review, 8(2), 341-370.

Watson, D., Clark, L. A., \& Tellegen, A. (1988). Development and validation of brief measures of positive and negative affect: The PANAS scales. Journal of Personality and Social Psychology, 54(6), 1063-1070.

Wu, Y. W., \& Zhao, Q. (2010). Higher education expansion and employment of university graduates. Economic Research Journal, 9, 93-108.

Xu, Z. C., \& Xiao, G. L. (2008). On nurturing social foundation for constructing innovative nation. China Soft Science Magazine, $6,48-55$.

Zhang, M. J., Law, K. S., \& Lin, B. (2016). You think you are big fish in a small pond? Perceived overqualification, goal orientations, and proactivity at work. Journal of Organizational Behavior, 37(1), 61-84.

\section{Submit your manuscript to a SpringerOpen ${ }^{\circ}$ journal and benefit from:}

- Convenient online submission

- Rigorous peer review

- Open access: articles freely available online

- High visibility within the field

- Retaining the copyright to your article

Submit your next manuscript at $\boldsymbol{s p r i n g e r o p e n . c o m ~}$ 